\title{
Moral Outrage and Pragmatism: Explanations for Collective Action
}

\author{
Joanne Martin \\ Stanford University \\ PhILIP BRICKMAN $\dagger$ \\ University of Michigan
}

AND

Alan Murray

Stanford University

Received November 17, 1983

Two explanations for collective behavior were contrasted. The first, exemplified by relative deprivation theory, stresses the importance of feelings of moral outrage and perceived economic injustice. The second focuses on more pragmatic considerations, such as the availability of resources for mobilization. The present study examines these explanations for collective behavior in a laboratory setting. Subjects were members of a disadvantaged group. In a $3 \times 2$ factorial design two independent variables were manipulated. The magnitude of pay inequality between the disadvantaged group and a more advantaged group was manipulated to be large, moderate, or small. Mobilization resources available to the disadvantaged group were manipulated to be either present or absent. In accord with predictions based on relative deprivation theory, as the magnitude of the inequality increased, stronger feelings of deprivation were expressed. However, contrary to relative deprivation theory, larger magnitudes of inequality and stronger feelings of deprivation were not associated with greater willingness to engage in legitimate

\section{$\dagger$ Deceased.}

An early version of this paper was presented at the annual meeting of the American Psychological Association, New York City, August 1981. The completed study was presented at the annual meeting of the Academy of Management, Dallas, Texas, August 1983. We thank Sim Sitkin and Mary Jo Hatch for assistance in the data collection and Faye Crosby, Kobert Folger, and David Messick for helpful comments on a draft of this article. Alan Murray is now an Assistant Professor at the School of Business, University of Alberta, Canada. Requests for reprints should be sent to Joanne Martin, Graduate School of Business, Stanford University, Stanford, CA 94305. 
or illegitimate forms of collective behavior. Instead, as predicted by some critics of relative deprivation theory, willinginess to engage in illegitimate forms of collective behavior was affected only by a pragmatic consideration: the presence or absence of mobilization resources.

Revolutions are often described as struggles for people's hearts and minds, in which feelings about injustice play a major role. Such discussions assume or assert that rebellious forms of collective behavior will not occur unless the disadvantaged come to feel morally outraged about their unjust treatment (e.g., Aristotle, 1962; Brickman, Folger, Goode, \& Schul, 1981; Fanon, 1963; Moore, 1978). For example, one review of this literature dismisses research on outrage and perceived injustice as "obvious and trite, for surely only angry men turn to revolution" (Kramnick, 1972, p. 56).

\section{THE RELATIVE DEPRIVATION EXPLANATION OF COLLECTIVE ACTION}

Relative deprivation (RD) theory elaborates the moral outrage explanation for collective behavior. The RD argument contains two essential parts:

(1) Some aspect of the distribution of outcomes (such as the magnitude of inequality or a change in prosperity levels) causes feelings of deprivation (such as discontent, outrage, resentment, or perceived injustice), and

(2) feelings of deprivation are associated with individual willingness to engage in collective behavior.

There is controversy about the validity of these two propositions, in part because the empirical evidence is inconclusive. The majority of the relevant studies have attempted to find a direct association between objective outcomes and collective behavior, without measuring feelings of deprivation (Bernstein \& Crosby, 1980; Cook, Crosby, \& Hennigan, 1977; Grofman \& Muller, 1973; Martin \& Murray, 1984). This is unfortunate, because one's objective position in a distribution of outcomes is not an accurate predictor of one's feelings of deprivation. Deprivation is labeled "relative" because often the people who feel the most deprived are not those who are objectively the most destitute (Runciman, 1966; Stouffer et al., 1949).

This unfortunate decision is made for understandable reasons. It is difficult to obtain data about participants' feelings immediately prior to such activities as the French revolution or the Watts riots. For similar reasons, these studies often do not include measures of individual willingness to engage in collective action. Instead, aggregate measures are used, such as the frequency of civil disorders or the timing of the onset of a revolution.

Given these methodological problems, it is not surprising that these studies come to differing conclusions about the relationship between 
outcome distributions and collective behavior. Some of these studies propose that pessimism, triggered by unchanging or deteriorating economic conditions, serves as a trigger for collective action (Abeles, 1976; Caplan \& Paige, 1968; Pettigrew, 1980). Other studies conclude that optimism and rising expectations, prompted by improving economic conditions, catalyze collective behavior (e.g., Davies, 1969; Gurr, 1970). The remainder of these studies fail to find a consistent or clear-cut relationship between economic conditions and collective action (e.g., McPhail, 1971; Snyder \& Tilly, 1980; Spilerman, 1970).

A second type of study has focused on part 2 of the RD argument, seeking an association between feelings of deprivation and individual willingness to engage in collective action. Again, the empirical record is mixed, primarily because these studies measure different types of deprivation. General deprivation is discontent, for example, with one's job, which includes no specified comparative referent. Egoistic deprivation is discontent caused by a comparison of one's own outcomes to those of someone similar. In accord with recent research on the effects of selfinterest on political attitudes (e.g., Sears, Lau, Tyler, \& Allen, 1980), general and egoistic measures of deprivation have generally failed to predict collective behavior (e.g., Crosby, 1982; Grofman \& Muller, 1973; Martin \& Murray, 1983; Miller, Bolce, \& Halligan, 1977), although exceptions have been found (Crawford \& Naditch, 1970; Sears \& McConahay, 1973).

Fraternal deprivation is discontent that stems from a comparison between disadvantaged and advantaged groups. Perhaps because collective action is an attempt to change the way outcomes are distributed to an entire group, efforts to find an association between fraternal deprivation and collective action have generally been more successful. Feelings of fraternal deprivation have been associated with student protest behavior, militant political attitudes, and willingness to be aggressive in a laboratory setting (Guimond, 1979; Guimond \& Dube-Simard, 1983; Ross, Thibaut, \& Evenbeck, 1971). Vanneman and Pettigrew (1972) found that people who felt both egoistically and fraternally-that is, doubly-deprived, were more likely to engage in one form of collective behavior: voting incumbent politicians out of office. However, efforts to find an association between feelings of fraternal deprivation and willingness to engage in collective action in work settings have been less successful (De Carufel, 1981; Graham, 1983; Martin, 1981).

The occasional, if not universal, failure of $\mathrm{RD}$ research to demonstrate a link to collective behavior could be due to (1) a failure to measure feelings of deprivation in a consistent and appropriate manner, (2) a problem with part 1 of the RD argument, (3) a problem with part 2, or (4) a problem with both parts. 


\section{THE PRAGMATIC EXPLANATION FOR COLLECTIVE ACTION}

Other explanations for collective behavior have a coolly pragmatic tone. Rather than studying emotions of outrage and perceived injustice, attention is focused on structural factors, relevant to the distribution of power and resources in a system (e.g., McCarthy \& Zald, 1977; Oberschall, 1978). The central argument is that the disadvantaged will engage in collective action if they have the resources believed necessary for successful mobilization, for example, opportunities to come into contact with each other (e.g., Liebow, 1967; McCall, 1970; McPhail, 1971; Smelser, 1980), the power that comes from offering services essential for the effective functioning of the system (e.g., Skocpol, 1979; Smelser, 1980) and the incentive of knowing that other, similarly disadvantaged groups have mobilized (e.g., Tilly, 1978).

There is an extreme version of the pragmatic position. Its advocates note that rebellious collective action has been associated with improving and deteriorating levels of prosperity, with stability and with change, and with increases and decreases in the magnitudes of inequality between advantaged and disadvantaged groups. They conclude that economic conditions may be relatively unimportant contributors to collective action (see Kramnick, 1972, for a review). Further, they note that it is possible to be deeply angry about an injustice, yet not engage in any kind of action. According to this extreme version of the pragmatic approach, if people have the resources for potentially effective mobilization, they will engage in collective action-even in the absence of potentially aggravating economic conditions, even if they do not feel unjustly treated (cf. Linewebber, Barr-Bryan, \& Zelditch, 1983; McCarthy \& Zald, 1977; Tilly, 1978). Thus, acting from self-interest rather than moral righteousness, people take what they can get.

\section{EXAMINING THE RELATIVE MERITS OF THE TWO EXPLANATIONS}

The present study is an attempt to explore these issues using experimental methodology in a laboratory setting. Subjects were members of a disadvantaged group. In a $3 \times 2$ factorial design, two independent variables were manipulated. The magnitude of pay inequality, between the disadvantaged group and a more advantaged group, was manipulated to be large, moderate, or small. Mobilization resources available to the disadvantaged group were manipulated to be either present or absent. Dependent variables included measures of fraternal deprivation, egoistic deprivation, and individual willingness to engage in a variety of collective behaviors aimed at reducing the pay inequality.

This design can be used to test alternative explanations for collective action. According to the pessimistic version of RD theory, as the magnitude of the pay inequality increases, feelings of deprivation should be stronger 
and willingness to engage in collective behavior should be greater. According to the optimistic version of RD theory, as the magnitude of the pay inequality decreases, feelings of deprivation should be stronger and willingness to engage in collective action should be greater. If the pragmatic approach is correct, collective behavior should be greater when mobilization resources are present rather than absent.

\section{METHOD}

\section{Subjects}

Subjects were 90 females recruited for a study of "pay satisfaction" and were paid $\$ 5$ each. All subjects were currently, or had been, employed full time. ${ }^{1}$ Subjects were randomly assigned to conditions. Cell sizes were unequal, ranging from 11 to 18 subjects.

\section{Procedure}

Upon arriving at the laboratory, subjects were greeted by an experimenter who announced that the study would focus on pay levels at California Oil Company (Cal Oil). Subjects were told that they would see a slide and tape presentation describing the company and the requirements of a sales manager position there. The tape recording described, in informal language, the responsibilities and daily activities of actual sales managers at an oil company. While the tape recording was played, a coordinated set of slides was shown. These slides portrayed three sales managers at work, for example, talking on the telephone or completing paper work in their offices. One of the pictured sales managers was female; the other two were male. After the slide and tape show, the subjects were handed "supplemental fact sheets," which contained "some facts about the current situation of sales managers at Cal Oil." These fact sheets contained the experimental manipulations. After studying the fact sheets, the subjects completed a questionnaire concerning their opinions about the sales manager job at Cal Oil. This questionnaire included the dependent measures and manipulaton checks. The experimenter then led an informal discussion about the study and thanked the subjects for their participation. All subjects were paid $\$ 5$ and subsequently received a brief report of the results of the study.

\section{Experimental Manipulations}

Because the experimental manipulations were contained in the supplemental fact sheets, the experimenter remained blind to the conditions to which the subjects had been assigned. The fact sheet presented the results of a recent survey conducted by members of the compensation department at $\mathrm{Cal}$ Oil. The survey focused on the financial rewards received by sales managers. Such rewards included a base salary, bonuses, commissions, chances for promotion, as well as "executive perks" such as lavish expense accounts and access to company cars. 'The survey measured the percentage of female sales managers who were receiving financial treatment equal to that received by comparable male sales managers. In the large inequality condition, only $2 \%$ of the female sales executives were receiving

${ }^{1}$ In order to maximize subjects' anonymity, demographic data were not collected. Informal conversations during debriefing sessions indicated that the sample was diverse. Occupations included waitress, accountant, lawyer, clerical worker, teacher, nurse, and personnel executive. Ages ranged from early 20 s to late $60 \mathrm{~s}$. Some subjects had not finished high school, while others had completed some postgraduate work. The subjects participated in one of four sessions in groups comprised of $11,19,26$, or 34 individuals. Preliminary data analyses revealed no significant differences among the testing groups. 
financial benefits equal to those of comparable males. In the moderate inequality condition, the percentage was $12 \%$, and in the small inequality condition, the percentage was $88 \%$. (Pretests indicated that $100 \%$ equality was considered unrealistic.)

Three types of mobilization resources were manipulated to be simultaneously present or absent. In conditions where the three mobilization factors were present, the female sales managers had frequent formal and informal contact with each other, their sales management skills were critical for the survival of the firm and difficult to replace, and female executives at another corporation had formed themselves into a formal group. In conditions where mobilization factors were absent, the female sales managers had little formal or informal contact, the sales manager position was less cssential for the firm's survival, as many other employees had the requisite marketing skills, and no mention was made of female executives at other organizations forming formal groups.

\section{Dependent Measures}

All dependent measures asked subjects to respond as if they were sales managers at Cal Oil. Two items focused on the treatment of the female sales managers as a group, as compared to the male sales managers: "To what extent are female sales managers as a group being treated unjustly?" and "To what extent does the treatment of the female sales managers as a group make you feel discontent?" Responses to these items were summed to create an index of fraternal deprivation. These and all other deprivation questions were answered on 100-point scales with the endpoints labeled not at all unjustly (discontent) and totally unjustly (discontent).

The questionnaire indicated to each subject individually that, if she were to work at Cal Oil as a sales manager, her personal financial compensation level would be relatively low for this position: "Although you are not absolutely sure, you strongly suspect that your personal financial rewards (including base salary, bonuses, executive perks, etc., are less than those received by other sales managers." This information was credible, as the experience levels of the subjects were similar to those of the lower paid sales managers portrayed in the slide and tape show. 'Two dependent measures focused on the subjects' reactions to their individual pay levels: "To what extent do you think your personal financial treatment is unjust?" and "To what extent does your personal financial treatment make you feel discontent?" Responses to these two items were summed, to create an index of egoistic deprivation.

Subjects also assessed their willingness to engage in a variety of collective behaviors. In order to maximize the chances of finding a relationship between feelings of deprivation and willingness to engage in collective action, a wide range of behaviors were measured. Subjects were told that "a meeting has been called for all sales managers to discuss the issue of whether male and female sales managers have been receiving equal financial treatment. Assuming you could attend the meeting, what is the likelihood that you would engage in each of the activities listed below?" The likelihood of each behavior was rated on a 100 -point scale, with $0 \%$ indicating no chance of participation and $100 \%$ indicating certainty of engagement in the activity.

Some of the activities were responses to compensation grievances that would be considered standard and legitimatc in most organizational settings: "attend the meeting; urge two or three friends to be sure and attend the meeting; donate money to cover incidental expenses for the meeting (if so, how much?); distribute reminders about the meeting; agree to serve on the five-member coordinating committee for future meetings; serve as chairperson for the meeting; argue that a delegation carry any complaints the group may have to upper management." Other activities had a more illegitimate tone, in the sense that norms of politeness, ethics, or company loyalty would be broken: "give the cold shoulder to someone who refused to attend the meeting; suggest the group engage in a short work slow-down, for example, by showing up 30 minutes late for a sales review session; suggest the group 
engage in petty acts of sabotage, such as deliberately making mistakes in sales report procedures; suggest that the group picket the front door of Cal Oil during lunch hour."

In addition, noncollective behavioral options were measured: "try harder to improve your performance on the job, for example by selling more; try less hard on the job, for example by sometimes taking it easy rather than putting forth that extra effort: take night courses to improve your marketing skills; begin to look for a job at another company."

\section{Manipulation Checks}

After responding to the dependent measures, subjects were asked to recall (with no access to the supplemental fact sheet), "What percentage of the female sales managers received financial rewards less than those of comparable male sales managers?" This item assessed the perceived magnitude of inequality.

Subjects were asked separate questions about the three mobilization resources: "Do channels already exist for formal and informal contact and communication among female sales managers? Is the sales manager position critical or peripheral to the operation of Cal Oil? Do you think that female executives at other firms like Cal Oil have mobilized themselves into formal groups?" All manipulation checks were answered on 100-point scales with endpoints labeled appropriately.

\section{RESULTS}

All dependent variables were analyzed with 3 (magnitude of inequality: large, moderate, or small) $\times 2$ (mobilization resources: present or absent) analyses of variance.

\section{Manipulation Checks}

Subjects' perceptions of the magnitude of inequality between the male and female sales managers were quite accurate. As expected, the magnitude of the manipulated inequality had a significant main effect on these estimates, $F(2,82)=4.14, p<.03$. Each level of inequality contributed equally to this effect. No other significant main effect or interaction was found.

Manipulations of two of the three mobilization resources were also successful. As expected, there was a significant main effect of manipulated mobilization resources on subjects' assessments of the preexisting channels for contact among the female sales managers and on their estimates of whether the sales manager position was critical to the operation of Cal Oil, $F(2,82)=31.25, p<.0001$, and $F(2,82)=216.64, p<.0001$, respectively. No other main effects or interactions in these analyses were significant. Contrary to expectations, subjects in all conditions were equally likely to say that female executives at other organizations had formed a formal group. The failure to manipulate this third mobilization resource does not prevent use of this independent variable, because the remaining two resources were successfully manipulated.

\section{Feelings of Deprivation}

Table 1 presents the deprivation data. The magnitude of the inequality between the male and female sales managers had a significant main effect 
TABLE 1

Mean Feelings of Deprivation as a Function of Magnitude of Inequality and Resources for MobILIZATION

\begin{tabular}{lcc} 
& \multicolumn{2}{c}{ Feelings of deprivation } \\
\cline { 2 - 3 } Mobilization resources & Fraternal & Egoistic \\
\hline Present & & 87.78 \\
$\quad$ Large inequality & 89.94 & 90.71 \\
Moderate inequality & 88.93 & 65.00 \\
Small inequality & 40.83 & 93.82 \\
Absent & & 85.29 \\
Large inequality & 85.25 & 70.45 \\
Moderate inequality & 83.14 & \\
Small inequality & 49.55 & \\
\hline
\end{tabular}

Note. The higher the score, the greater the feelings of deprivation (discontent and injustice).

on the female subjects' feelings of fraternal and egoistic deprivation, $F(2$, $82)=36.52, p<.0001$, and $F(2,82)=9.10, p<.0001$, respectively. In accord with the pessimistic version of RD theory, feelings of deprivation were stronger in conditions where the magnitude of inequality was larger. Although the magnitude of inequality had a slightly stronger effect on fraternal, rather than egoistic, deprivation, the pattern of results for the two types of deprivation was similar. Thus, in Vanneman and Pettigrew's terms, as the magnitude of inequality increased, subjects were more likely to express double - that is, both fraternal and egoistic-deprivation. The presence or absence of mobilization resources had no significant main effect on feelings of deprivation and no significant interaction was found, all $F^{\prime}$ 's $<1$.

\section{Individual Willingness to Engage in Collective Action}

Table 2 presents the collective behavior data. The likelihoods of engaging in all the legitimate forms of collective behavior were summed to create an index. A similar index was created for the illegitimate forms of collective behavior. These indexes were used to calculate the means reported in Table 2 and the analyses of variance results reported below. Behavioral items were assigned to these indexes on the basis of a priori conceptual distinctions. These data were also analyzed for each dependent variable separately. A variety of other conceptually and empirically designed indexes of collective behavior were also used. In order to determine if willingness to engage in the noncollective behaviors affected the results reported below, all analyses of variance were repeated, using various combinations of the noncollective behaviors as covariates. The results of all these analyses did not substantively differ from those described below. 
TABLE 2

Mean Willingness to Engage in Collective Behavior as a Function of Magnitude of INEQUality and ResourCes for Mobilization

\begin{tabular}{lcc}
\hline & \multicolumn{2}{c}{ Collective behaviors } \\
\cline { 2 - 3 } Mobilization resources & Legitimate & Illegitimate \\
\hline Present & & \\
$\quad$ Large inequality & 71.42 & 14.15 \\
Moderate inequality & 59.25 & 11.84 \\
Small inequality & 67.81 & 9.42 \\
Absent & & \\
Large inequality & 69.14 & 6.02 \\
Moderate inequality & 69.42 & 5.27 \\
Small inequality & 61.20 & 5.83 \\
\hline
\end{tabular}

Note. The higher the score, the greater the likelihood of engaging in the behaviors.

The independent variables did not affect willingness to engage in the legitimate forms of collective behavior. No significant main effects or interaction was found, all $F$ 's $<2$. In all conditions, approximately two thirds of the subjects were willing to engage in these standard, legitimate forms of collective behavior. Mobilization resources, however, did have a significant main effect on willingness to engage in the illegitimate forms of collective behavior, $F(2,82)=5,23, p<.025$. Such behavior was more likely in the conditions where mobilization resources were present. The magnitude of inequality had no significant main effect on willingness to engage in these illegitimate forms of collective behavior, and no significant interactions were found, all $F$ 's $<1$. Thus, feelings of fraternal and egoistic deprivation-even double deprivation-were not related to individual willingness to engage in collective action.

\section{DISCUSSION}

The results of this study support the pessimistic version of part 1 of the RD argument; as the magnitude of inequality increased, stronger feelings of egoistic and fraternal deprivation were expressed. The data, however, provided no support for the Part 2 of the RD analysis; larger magnitudes of inequality and stronger feelings of deprivation were not associated with greater willingness to engage in legitimate or illegitimate forms of collective behavior. Instead, willingness to engage in illegitimate forms of collective behavior was influenced by the presence or absence of mobilization resources.

\section{Limitations of the Design}

It is possible that magnitudes of inequality and feelings of deprivation impact willingness to engage in collective action, but the limitations of the present study prevented detection of these relationships. Perhaps 
greater magnitudes of inequality should have been studied, in order to focus on more severely disadvantaged groups, such as the poor or victims of severe racial discrimination. Perhaps feelings of injustice could have been intensified and willingness to engage in behaviors could have been more realistically assessed, if the study had not used a modified role play design, with pencil-and-paper measures of behavior. Role play studies of injustice, in particular, can produce misleading results (due to social desirability effects) if role playing subjects respond without becoming emotionally involved (Lerner, 1981). It is difficult, however, to design a study that avoids these limitations, elicits stronger feelings of moral outrage, and does not transgress ethical boundaries.

There are some reasons to believe that these limitations may not have strongly affected the results of the study. It was decided not to focus on a severely disadvantaged group because feelings of deprivation tend to be most intense among those who are moderately, rather than least, prosperous (Runciman, 1966; Stouffer et al., 1949). Efforts were made to enhance the mundane reality and external validity of the experimental setting by using job descriptions and pay levels from an actual company and recruiting adult subjects with full-time working experience. In order to minimize social desirability effects, questionnaire responses were written and anonymous, and no demographic information about individual subjects was collected. In addition, the emotional involvement of the subjects was evident during debriefing sessions. In spite of these considerations, however, it is possible that one or more of these limitations may have made it difficult to detect a relationship to collective behavior.

\section{Considering the Personal Costs of Behaviors}

It is possible that the results of the present study were affected by the costs of engaging in various forms of collective behavior. The legitimate behaviors studied involved relatively low personal costs. In addition, the subjects may have brought a threshold level of perceived injustive with them into the laboratory. There are three indications that indirectly support this threshold contention: the pretest evidence that a $100 \%$ equality manipulation would not be credible, the failure of one of the resource availability manipulations, because all subjects were equally likely to assume that females at other institutions had organized themselves into a formal group, and the emotional involvement of subjects during the debricfing sessions. If the legitimate behaviors were relatively low cost, and if subjects brought a threshold level of perceived injustice into the laboratory, then the presence of even slight magnitudes of inequality may have been sufficient to trigger these hehaviors. In this context, it is not surprising that approximately two thirds of the subjects in all conditions were willing to engage in the legitimate forms of collective behavior. 
The illegitimate behaviors in the present study may have entailed relatively high costs for these subjects, in part because females are much less likely than males to engage in aggressive behavior (Maccoby \& Jacqulin, 1974). Fewer than $15 \%$ of the subjects in any condition were willing to engage in the illegitimate forms of collective behavior. Perhaps the subjects' general unwillingness to engage in these behaviors may have created a "floor effect," thereby limiting the extent to which willingness to engage in these behaviors could be differentiated as a function of magnitudes of inequality or intensity of feelings of deprivation.

If this cost analysis is correct, the results of the present study may help explain the mixed results of previous RD research. The previous studies that failed to find a relationship to collective action focused on high-cost behaviors, such as participation in revolution and violent riots. More successful studies tended to focus on somewhat less costly behaviors, such as student participation in peaceful protests, willingness to advocate militant attitudes, and aggression against strangers in a laboratory setting. These results suggest that changes in the magnitude of inequality or the intensity of feelings of injustice might have greater impact on moderately costly forms of collective behavior. Future RD research could easily incorporate pretest data that scaled personal costs associated with various types of collective behavior.

\section{Moral Outrage and Pragmatism}

In spite of limitations in design and in the types of behavior studied, the present study did elicit considerable variation in feelings of deprivation and did examine a wide range of collective behaviors. The results of the present study are consistent with a third interpretation, in which feelings of injustice play a secondary role. In this domain, as in other domains of psychological research, emotional attitudes may be loosely coupled with behavior. Although increases in the magnitude of inequality may cause feelings of injustice, those feelings may make a relatively small contribution to decisions about participation in collective action. Instead, those decisions may be primarily made on a pragmatic rather than emotional basis, including consideration, for example, of the availability of mobilization resources and the personal costs of the behavior.

If this pragmatic explanation is correct, then how can it be reconciled with the results of the previous research that has sporadically found support for part 2 of the RD argument? The pragmatic explanation portrays rebels as rational cost-benefit analysts, who have calculated that they have the potential of gaining something at an acceptable level of risk. Some participants in collective actions may find the RD explanation for their behavior, which implies they are morally outraged victims of injustice, publicly and personally more appealing. When people are asked, during or after the fact, to explain their participation in collective action, many 
may prefer moral outrage explanations which fit the RD argument, rather than admit to themselves, or to others, their more pragmatic calculations. Researchers, then, may take this rhetoric to be a full and accurate description of the causes of collective action, concluding that "surely only angry men turn to revolution." Instead, these people may be offering self-enhancing, post hoc rationalizations for their behavior.

\section{REFERENCES}

Abeles, K. P. (1976). Kelative deprivation, rising expectations and black militancy. Journal of Social Issues, 32, 119-137.

Aristotle (1962). Politics (E. Barker, Ed.) New York: Univ. of Oxford Press.

Bernstein, M., \& Crosby, F. (1980). An empirical examination of relative deprivation theory. Journal of Experimental Social Psychology, 16, 442-456.

Brickman, P., Folger, R., Goode, E., \& Schul, Y. (1981). In M. J. Lerner \& S. C. Lerner (Eds.), The justice motive in social behavior. New York: Plenum.

Caplan, N., \& Paige, J. M. (1968). A study of ghetto rioters. Scientific American, 219(2), $15-22$.

Cook, T. D., Crosby, F., \& Hennigan, K. K. (1977). The construct validity of relative deprivation. In J. M. Suls \& R. L. Miller (Eds.), Social comparison processes. New York: Wiley.

Crawford, T. J., \& Naditch, M. (1970). Relative deprivation, powerlessness, and militancy: The psychology of protest. Psychiatry, 33, 208-223.

Crosby, F. J. (1982). Relative deprivation and working women. New York: Oxford Univ. Press.

Davies, J. C. (1969). The J-curve of rising and declining satisfaction as a cause of some great revolutions and a contained rebellion. In H. D. Graham \& T. R. Gurr (Eds.), The history of violence in America. New York: Bantam Books.

De Carufel, A. (1981). The allocation and acquisition of resources in times of scarcity. In M. J. Lerner \& S. C. Lerner (Eds.), The justice motive in human behavior. New York: Plenum.

Fanon, F. (1963). The wretched of the earth. New York: Grove.

Graham, J. (1983). Dissent in organizations as a response to perceived injustice. In R. Bies (Chair), Justice: Beyond equity theory. Symposium conducted at the annual meeting of Academy of Management, Dallas, TX.

Grofman, B. N., \& Muller, E. N. (1973). The strange case of relative gratification and potential for political violence: The V-curve hypothesis. American Political Science Review, 67, 514-539.

Guimond, S. (1979). L'interpretation des inegalites economiques et sa relation au mecontentement social et a la perception de differences culturelles. Unpublished master's thesis, University of Montreal, Canada.

Guimond, S., \& Dube-Simard, L. (1983). Relative deprivation theory and the Quebec nationalist movement: The cognition-emotion distinction and the personal-group deprivation issue. Journal of Personality Social Psychology, 44 (3), 526-535.

Gurr, T. R. (1970). Why men rebel. Princeton, NJ: Princeton Univ. Press.

Homans, G. C. (1974). Social behavior: Its elementary forms. New York: Harcourt Brace Jovanovich.

Kramnick, I. (1972). Reflections on revolution: Definition and explanation in recent scholarship. History and Theory, 11, 26-63.

Lerner, M. J., \& Lerner, S. C. (Eds.). (1981). Justice motive in social behavior. New York: Plenum.

Liebow, E. (1967). Tally's corner. Boston, MA: Brown.

Linewebber, D., Barr-Bryan, B., \& Zelditch, M. (1983). Effects of legitimate authority's 
justification of inequality on the mobilization of revolutionary coalitions. Unpublished manuscript, Stanford University.

Maccoby, E., \& Jacqulin, C. (1974). The psychology of sex differences. Stanford, CA: Stanford Univ. Press.

Martin, J. (1981). Relative deprivation: A theory of distributive injustice for an era of shrinking resources. In L. L. Cummings \& B. M. Staw (Eds.), Research in organizational behavior (Vol. III). Greenwich, CN: JAI Press.

Martin, J., \& Murray, A. (1983). Distributive injustice and unfair exchange. In K. S. Cook \& D. M. Messick (Eds.), Theories of equity: Psychological and sociological perspectives. New York: Praeger.

Martin, J., \& Murray, A. (1984). Catalysts for collective violence: The importance of a psychological approach. In R. Folger (Ed.), The sense of injustice: Social psychological perspectives. New York: Plenum.

McCall, M. (1970). Some ecological aspects of Negro slum riots. In J. Gusfield (Ed.), Protest, reform, and revolt. New York: Wiley.

McCarthy, J. D., \& Zald, M. N. (1977). Resource mobilization and social movement: A partial theory. American Journal of Sociology, 82, 1212-1241.

McPhail, C. (1971). Civil disorder participation: A critical examination of recent research. American Sociological Review, 36, 1058-1073.

Miller, A., Bolce, L., \& Halligan, M. (1977). The J-curve theory and the black urban riots. The American Political Science Review, 71, 964-982.

Moore, B. (1978). injustice: The social bases of obedience and revolt. White Plains, NY: Sharpe.

Oberschall, A. (1978). Theories of social conflict. Annual Review of Sociology, 4, 291315.

Olson, M. (1971). The logic of collective action. Cambridge, MA: Harvard Univ. Press.

Pettigrew, T. (1964). A profile of the Negro American. New York: Van Nostrand.

Pettigrew, T. (1980). New patterns of racism: American race relations since the sixties. Colloquium presented at Graduate School of Business, Stanford University, Stanford, CA.

Ross, M., Thibaut, J., Evenbeck, S. (1971). Some determinants of the intensity of social protest. Journal of Experimental Social Psychology, 7, 401-418.

Runciman, W. G. (1966). Relative deprivation and social justice: A study of attitudes to social inequality in twentieth century England. Berkeley, CA: Univ. of California Press.

Sears, D. O., Lau, R. R., Tyler, T., \& Allen, J. M., Jr. (1980). Self-interest versus symbolic politics in policy attitudes and presidential voting, American Political Science Review. 74, 670-684.

Sears, D. O., \& McConahay, J. B. (1973). The politics of violence. Boston, MA: Houghton Mifftin.

Skocpol, T. (1979). States and social revolutions. Cambridge: Cambridge Univ. Press.

Smelser, N. (1980). Theoretical issues of scope and problems. In M. D. Pugh (Ed.), Collective behavior: A source book. St. Paul, MN: West (Reprinted from The Sociological Quarterly, 1964, 5, 116-122).

Snyder, D., \& Tilly, C. (1980). Hardship and collective violence in France, 1930-1960. In M. D. Pugh (ed.), Collective behavior: A source book. St. Paul, MN: West (Reprinted from Amerian Sociological Review, 1972, 37, 520-522.)

Spilerman, S. (1970). The causes of racial disturbances: A comparison of alternative explanations. American Sociological Review, 35, 627-649.

Stouffer, S., Lumsdaine, A., Lumsdaine, M., Williams, R., Smith, M., Janis, I., Starr, S., \& Cottrell, L. (1949). The American soldier. Princeton, NJ: Princeton Univ. Press.

Tilly, C. (1978). From mobilization to revolution. Reading, MA: Addison-Wesley.

Vanneman, R. D., \& Pettigrew, T. F. (1972). Race and relative deprivation in the urban United States. Race, 13, 461-486. 